\title{
A New Talitrid Genus and Species, Lowryella wadai, from Estuarine Reed Marshes of Western Japan (Crustacea: Amphipoda: Talitridae)
}

\author{
Hiroshi Morino ${ }^{1,3}$ and Hisashi Miyamoto ${ }^{2}$ \\ ${ }^{1}$ Department of Zoology, National Museum of Nature and Science, 4-1-1 Amakubo, Tsukuba, Ibaraki 305-0005, Japan \\ E-mail:morino631@gmail.com \\ 24-9 Kasumi, Maruoka-cho, Sakai, Fukui 910-0231, Japan \\ E-mail: dream_50000000690737@yahoo.co.jp \\ ${ }^{3}$ Corresponding author
}

(Received 19 May 2016; Accepted 4 October 2016)

http://zoobank.org/6FBE8B84-5689-4E76-A9E1-2E901AA8BCA1

\begin{abstract}
A new genus and species of talitrid amphipod, Lowryella wadai, is described from estuarine reed marshes facing the Bungo Channel, western Japan. This genus belongs to the 4-dentate, cuspidactylate group of talitrids and is characterized by having: (1) a short and slender antenna 2, (2) a mediodistally lobate article 2 and reduced article 4 of the maxillipedal palp, (3) a deeply subchelate gnathopod 1 in both sexes, (4) a bulge on the basis and ischium of female gnathopod 1, (5) a marginally bare outer ramus of uropod 1, and (6) a telson lobe armed only with apical robust setae. Several genera including palustral talitrids display features in common with this new genus, but the character combination shown above distinctly separates Lowryella from them. Lowryella is the first stenotopic representative of the Talitridae from estuarine marshes in Japan.

Key Words: Crustacea, Amphipoda, Talitridae, Lowryella wadai, new genus, new species, estuary, reed marsh, Japan.
\end{abstract}

\section{Introduction}

Salt marshes and mangrove swamps harbor two groups of Talitridae [for the Atlantic coast of North America, see Bousfield and Heard (1986); for southern Tasmania, see Richardson and Mulcahy (1996)]. One group are the beach fleas sensu Bousfield (1982), which are generally eurytopic. They occupy a wide range of habitats, including marine supralittoral beaches, estuaries, and sometimes also inland forests. Orchestia Leach, 1813, Platorchestia Bousfield, 1982, and Tethorchestia Bousfield, 1984 are representative genera of this group (Bousfield and Heard 1986; Richardson and Mulcahy 1996), and perhaps also the cosmopolitan genus Floresorchestia Bousfield, 1984, judging from habitat information compiled by Lowry and Springthorpe (2015a). The other group, the palustral talitrids of Bousfield (1984), are more or less stenotopic, comprising genera that occur mostly in coastal marine and estuarine habitats (Bousfield and Heard 1986; Richardson and Mulcahy 1996). One of the palustral genera, Uhlorchestia Bousfield, 1984, is endemic to the Spartina marshes on the Atlantic coast of North America, and the remaining five genera occur in the Southern Hemisphere. According to the model of the early evolution and the subsequent adaptive radiation of the Talitridae advanced by Bousfield (1984), the palustral talitrids occupy an ancestral position in the whole group and the beach fleas are considered to be a derived group.

Quite recently Lowry and Springthorpe (2015b) de- scribed a new genus, Tropicorchestia, with two new species from salt marshes of tropical Australia. They referred to these amphipods as "marsh hoppers", suggesting a strong habitat preference of this genus for the marshes. Morphologically Tropicorchestia is closer to the beach fleas than to the palustral talitrids (see Lowry and Springthorpe 2015b). It seems reasonable to assume that estuarine marshes in the world's temperate to tropical zones have been invaded by the local talitrid fauna, which have given rise to more or less endemic estuarine forms.

Eurytopic beach fleas have been recorded from estuarine habitats in Japan (see below) but no stenotopic genera or species have been reported from such places to date (Biodiversity Center of Japan 2007). Recently we examined a few peculiar amphipod specimens collected from reed marshes at two river mouths in western Japan. They proved to be talitrids with a unique combination of features that prevents their assignment to any known genera. A new genus and new species are erected for them herein, as the first known stenotopic estuarine talitrid from Japan.

\section{Materials and Methods}

The specimens were collected from two localities on the western coast of Shikoku and the eastern coast of Kyushu (Fig. 1) during an extensive survey of the littoral environment (tidal flats) at 157 points all over Japan, which focused on "Valuable Wetlands in Japan" (Biodiversity Center of 


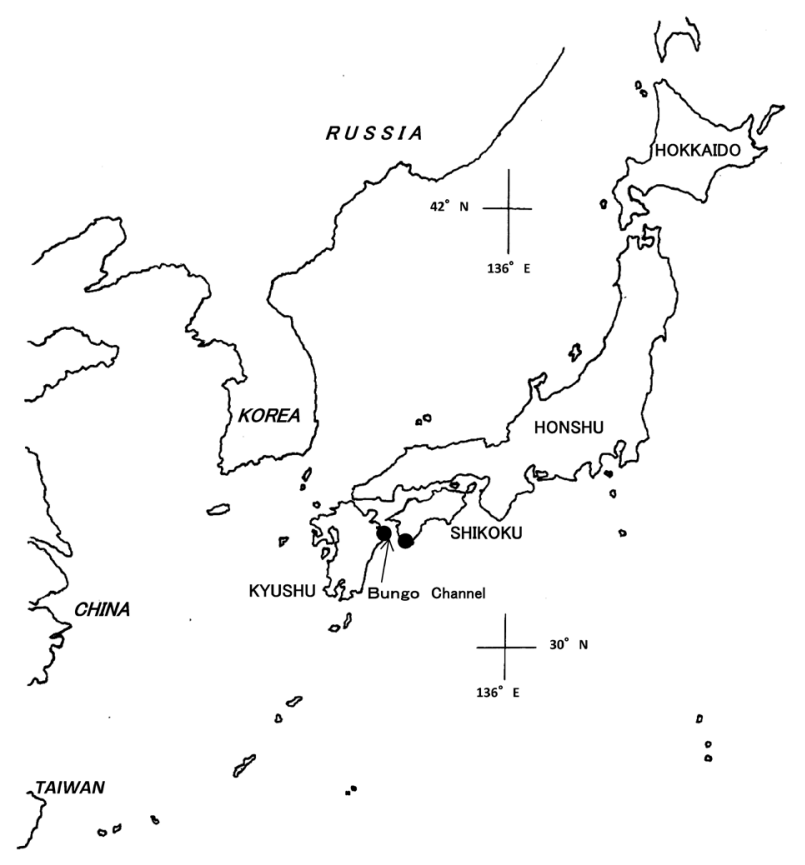

Fig. 1. Sampling sites of Lowryella wadai gen. et sp. nov.

Japan 2007). The talitrids from this survey were given to the first author by Dr K. Wada for identification, and part of this collection has preliminarily been published elsewhere (Biodiversity Center of Japan 2007).

In the present description, the general methodology follows Morino (2014). The specimens were dissected under a stereomicroscope (LEICA MZ8), and bodies and appendages were illustrated using an optical compound microscope equipped with a drawing tube (Nikon). The mandibles and maxilliped of the holotype were heavily infested by epizoans, so the allotype was utilized for the illustrations of these two mouthparts. For each specimen, the illustrated appendages were kept in separate tubes for each body part they attached to (i.e., head, pereonites, pleonites, and urosomites), and all tubes were put in a bottle together with the body. Body length was measured from the tip of the head to the tip of the telson along the straightened dorsal margin. The specimens studied are lodged in the collection of the National Museum of Nature and Science, Tsukuba (NSMT).

\section{Family Talitridae Rafinesque, 1815 Lowryella gen. nov.}

[New Japanese name: Yoshihara-hamatobimushi zoku]

Type species. Lowryella wadai sp. nov. (monotypic)

Diagnosis. Body size medium. Eyes large. Antenna 1 reaching anterior end of peduncular article 4 of antenna 2; peduncle longer than flagellum, with peduncular articles 1-3 subequal in length. Antenna 2 short and slender in both sexes, with flagellum subequal to peduncle in length. Upper lip lacking robust setae. Lacinia mobilis of left mandible 4-dentate, that of right mandible 3-dentate with fine scales. In maxilliped, outer margin of precoxa not stepped; palp articles 2 and 3 broad; article 2 mediodistally lobed; article 4 reduced, masked by apical robust setae on article 3 .
Gnathopod 1 deeply subchelate in both sexes (stronger in male); in male, merus, carpus, and propodus each with pellucid lobe, lateral surface of propodus with submarginal row of elongate robust setae; in female, posterodistal margins of basis and ischium each bearing small bulge with scabrous surface, propodus with broad pellucid lobe, lateral surface with submarginal row of elongate robust setae, palm slightly exceeding dactylus. Gnathopod 2 sexually dimorphic; in male, propodus large and powerfully subchelate, palmar margin almost straight, dactylus apically blunt; in female, basis broad and parallel-sided, merus with pellucid lobe, propodus mitten-shaped. Pereopods 3-7 cuspidactylate (bicuspate), locking robust-setae on propodi well-developed, meri and carpi in female stouter than those of male. Dactylus of pereopod 4 not pinched. Coxa of pereopod 4 wider than deep. Posterior lobe of coxa on pereopod 6 smoothly curved anteroventrally. Propodus of pereopod 7 in male with tuft of setae mediodistally. Coxal gill of gnathopod 2 largest and lobed, that of pereopod 3 smallest, those of pereopods 5 and 6 same in size; coxal gills of pereopods 3-6 convoluted. Oostegites subovate, with simple-tipped setae.

Pleonite side plates lacking marginal pits. Pleopods welldeveloped, peduncles marginally bare or with a few robust setae. Peduncle of uropod 1 with distolateral robust seta shorter than subdistal seta; inner ramus with single row of marginal robust setae, outer ramus with bare margin. Rami of uropod 2 subequal in length, bearing 1 or 2 marginal rows of robust setae. Uropod 3 with broad peduncle; ramus short. Telson lobe armed only with groups of apical robust setae.

Etymology. The new genus is named in honor of Dr James K. Lowry, who has contributed much to the taxonomy of the Talitridae and other amphipod groups.

Remarks. This new genus displays the following morphological features: (1) large eyes, (2) a short and slender antenna 2 in both sexes, (3) a 4-dentate lacinia mobilis of the left mandible, (4) a mediodistally lobate article 2 and reduced article 4 of the maxillipedal palp, (5) a deeply subchelate gnathopod 1 in both sexes, (6) a distinct pellucid lobe on the merus of male gnathopod 1, (7) a bulging basis and ischium of female gnathopod 1, (8) cuspidactylate pereopods, (9) a non-pinched dactylus of pereopod 4, (10) a distally setose propodus of male pereopod $7,(11)$ a small coxal gill of pereopod 6 (as large as that of pereopod 5), (12) a marginally bare outer ramus of uropod 1, and (13) only apical robust setae on the telson lobe. Among these, bulges on the basis and ischium of female gnathopod 1 and the small coxal gill of pereopod 6 are unique to this genus.

Lowryella belongs to the 4-dentate, cuspidactylate talitrids (Bousfield 1984) and shows morphological similarities to one genus of salt-marsh talitrid, Tropicorchestia, and two land-hopper genera, Mizuhorchestia Morino, 2014 and Nipponorchestia Morino and Miyamoto, 2015. This new genus, however, can be distinguished by the combination of the character states summarized in Table 1.

The beach-flea genus Traskorchestia Bousfield, 1982 has the cuspidactylate pereopods 3-7 like those of Lowryella, but the former is distinguishable from the latter in having a 
Table 1. Character matrix of Lowryella gen. nov. and three related genera.

\begin{tabular}{|c|c|c|c|c|}
\hline Characters & Lowryella & Tropicorchestia & Mizuhorchestia & Nipponorchestia \\
\hline Mxpd palp Art 2 & Lobate & Lobate & Non-lobate & Lobate \\
\hline F Gn 1 propodus & Deep-subchelate & $\begin{array}{l}\text { Shallow-subchelate } \\
\text { (or "parachelate") }\end{array}$ & Deep-subchelate & Deep-subchelate \\
\hline F Gn 1 basis and ischium & Bulging & Non-bulging & Non-bulging & Non-bulging \\
\hline M Gn 1 merus & With lobe & With lobe & With lobe & With or without lobe \\
\hline Per 6 gill & Subequal to Per 5 gill & Not known & $\begin{array}{l}\text { Twice larger than Per } \\
5 \text { gill }\end{array}$ & $\begin{array}{l}\text { Twice larger than Per } \\
5 \text { gill }\end{array}$ \\
\hline Distal setae on M Per 7 propodus & Present & Absent & Absent & Absent \\
\hline Pl 1-3 & Well-developed & Well-developed & Reduced & Reduced \\
\hline Margin on Up-1 outer ramus & Bare & Bare & $\begin{array}{l}\text { With } 1 \text { (rarely } 2 \text { ) robust } \\
\text { seta }\end{array}$ & Bare \\
\hline Robust setal clusters on $\mathrm{T}$ & Apical & Lateral and apical & Lateral and apical & Lateral and apical \\
\hline
\end{tabular}

Sources: Morino (2014); Lowry and Springthorpe (2015b); Morino and Miyamoto (2015a); this study. Abbreviations: Art, article; F, female; Gn, gnathopod; M, male; Mxpd, maxilliped; Per, pereopod; Pl, pleopods; T, telson lobe; Up, uropod.

5-dentate lacinia mobilis on the left mandible, marginal robust setae on the outer ramus of uropod 1, and lateral and apical robust setae on the telson lobe. Palustral talitrids of the genus Uhlorchestia also show morphological similarities with the new genus, sharing large eyes, a non-sexually dimorphic and slender antenna 2, a 4-dentate lacinia mobilis of the left mandible, a reduced article 4 of the maxillipedal palp, a deeply subchelate gnathopod 1 in both sexes (stronger in males), and well-developed pleopods. But Uhlorchestia differs from Lowryella in having a non-lobate article 2 of the maxillipedal palp, simplidactylate pereopods, marginal robust setae on the outer ramus of uropod 1, and both lateral and apical robust setae on the telson lobe.

Occupying the same type of habitat (salt marshes and estuaries) but quite distantly separated geographically (Uhlorchestia in the eastern Atlantic and Tropicorchestia in tropical Australia), the similarities between these two talitrids and the new genus are more easily attributable to convergent evolution than to a recent common ancestor. Japanese endemic genera Mizuhorchestia and Nipponorchestia are also similar to Lowryella, but inhabit the environment from coastal land to inland forest (Morino 2014; Morino and Miyamoto 2015a). Their developed coxal gill of the pereopod 6 and reduced pleopodal rami differ from the state of those appendages of Lowryella (Table 1), and could be ascribed to adaptation to terrestrial life (Friend 1986). Wildish (1988) suggested that the land colonization via estuarine habitats could be one of the possible routes for terrestrial talitrids. In the view of the above, it can be assumed that these three Japanese genera are phylogenetically closely related, and Lowryella could be a direct part of the ancestral lineage of the terrestrial talitrid genera in Japan. This hypothesis could be assessed by means of molecular phylogenic analysis.

\section{Lowryella wadai sp. nov.}

[New Japanese name: Yoshihara-hamatobimushi]

(Figs 2-5)

Type material. Holotype (NSMT-Cr 24358), male $9.9 \mathrm{~mm}$, Misho Bay (estuary of Sozu river, Phragmites marsh), Ainan-cho, Ehime Pref., 20 April 2004, K. Wada

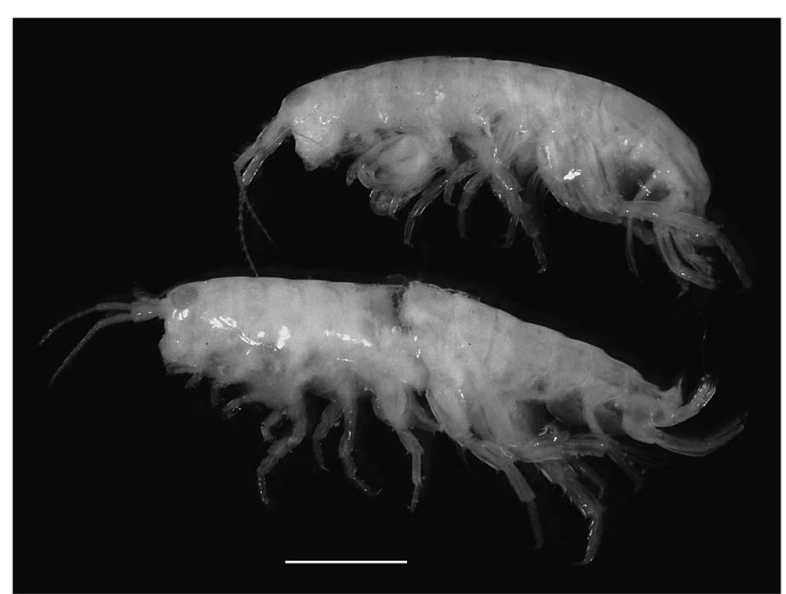

Fig. 2. Photos of fixed specimens of Lowryella wadai gen. et sp. nov. Upper, male $6.5 \mathrm{~mm}$ (paratype, NSMT-Cr 24360); lower, female $7.8 \mathrm{~mm}$ (paratype, NSMT-Cr 24362). Scale: $2 \mathrm{~mm}$.

coll. Allotype (NSMT-Cr 24359), female $8.2 \mathrm{~mm}$, same data as holotype. Paratypes: ovig. female (NSMT-Cr 24361), $8.0 \mathrm{~mm}$, same data as holotype; male (NSMT-Cr 24360), $6.5 \mathrm{~mm}$, same data as holotype; female (NSMT-Cr 24362), $7.8 \mathrm{~mm}$, same data as holotype; 2 juveniles (NSMT-Cr 24363), same data as holotype; ovig. female (NSMT-Cr 24364), estuary of Kitagawa river (Phragmites marsh), Nobeoka city, Miyazaki Pref., 5 June 2004, K. Wada coll.

Description of male (Holotype, $9.9 \mathrm{~mm}$ ). Eyes (Figs 2, 3A) large, longest diameter $c a$. half of head length, spherical in dorsolateral view, contiguous dorsally. Antenna 1 (Fig. 3B) with peduncular articles 1-3 subequal in length; flagellum with 4 articles. Antenna 2 (Figs 2, 3C) with peduncular article 5 subequal in length to articles 3 and 4 combined; flagellum with 10 articles.

Upper lip (Fig. 3D), lower lip (Fig. 3E), and maxillae 1and 2 (Fig. 3F, G) as described in generic diagnosis or illustrated in respective figures. Gnathopod 1 (Fig. 3L, M) with broad carpus and propodus; carpus $c a$. 1.3 times as long as propodus; propodus ca. 0.7 times as broad as long, with palmar margin transverse, far exceeding tip of dactylus; lateral surface of propodus with submarginal row of 5 setae. Gna- 


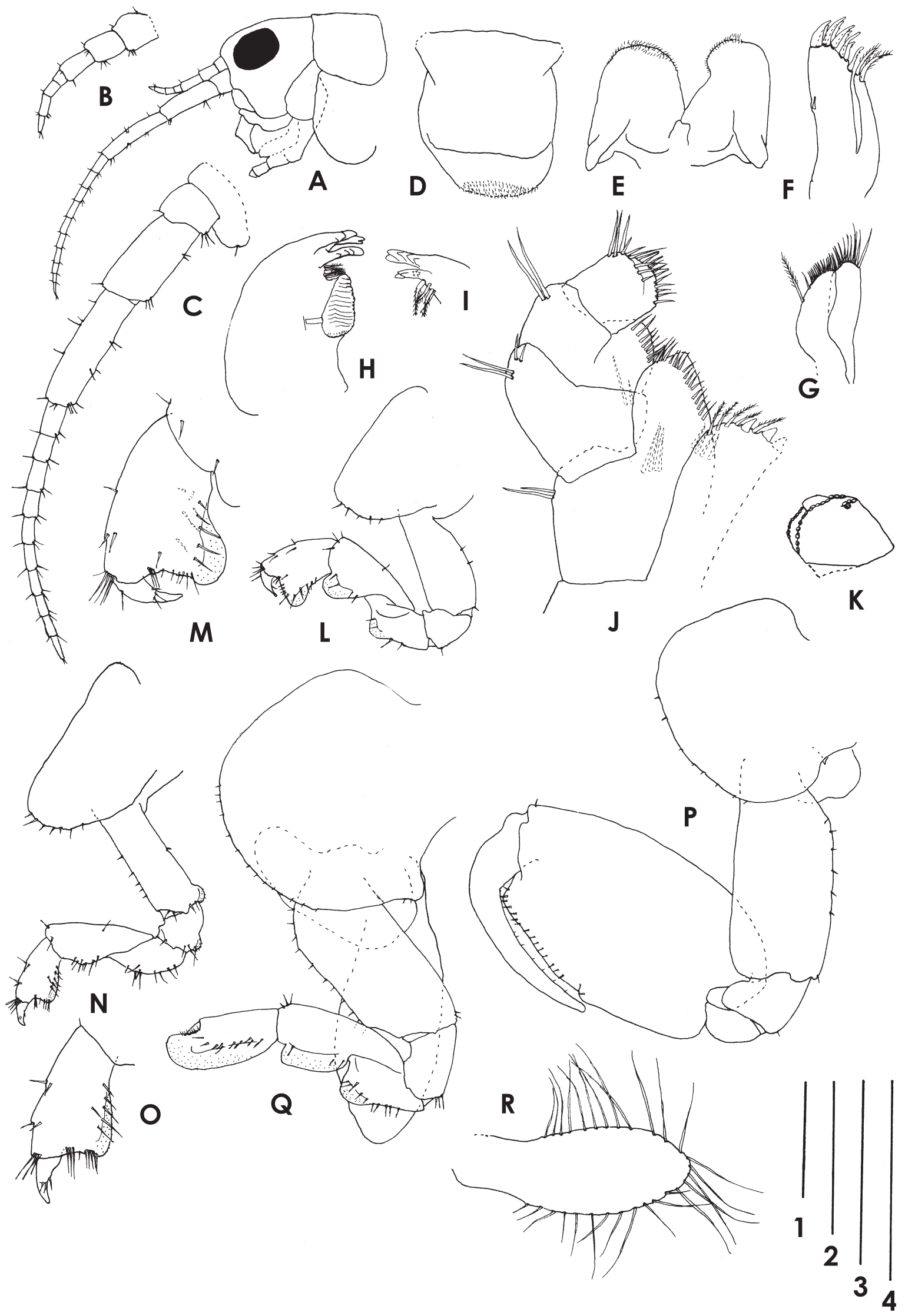

Fig. 3. Lowryella wadai gen. et sp. nov. Male $9.9 \mathrm{~mm}$ (holotype, NSMT-Cr 24358), A-G, L, M, P; ovig. female $8.2 \mathrm{~mm}$ (allotype, NSMT-Cr 24359), H-K, N, O, Q, R. A, head; B, antenna 1; C, antenna 2; D, upper lip; E, lower lip; F, maxilla 1; G, maxilla 2; H, left mandible; I, distal part of right mandible; J, maxilliped; K, articles 3 and 4 of maxillipedal palp (ventral view); L, N, gnathopod 1; M, O, distal articles of gnathopod 1; P, Q, gnathopod 2; R, oostegite of gnathopod 2. Scale 1, $0.5 \mathrm{~mm}$ for $\mathrm{N}$ and Q; scale 2, $1 \mathrm{~mm}$ for B and C; scale 3, $1 \mathrm{~mm}$ for L, P, and R, $0.4 \mathrm{~mm}$ for O; scale $4,2 \mathrm{~mm}$ for A, $0.5 \mathrm{~mm}$ for D-I, $0.2 \mathrm{~mm}$ for J, $\mathrm{K}$, and $\mathrm{M}$. 

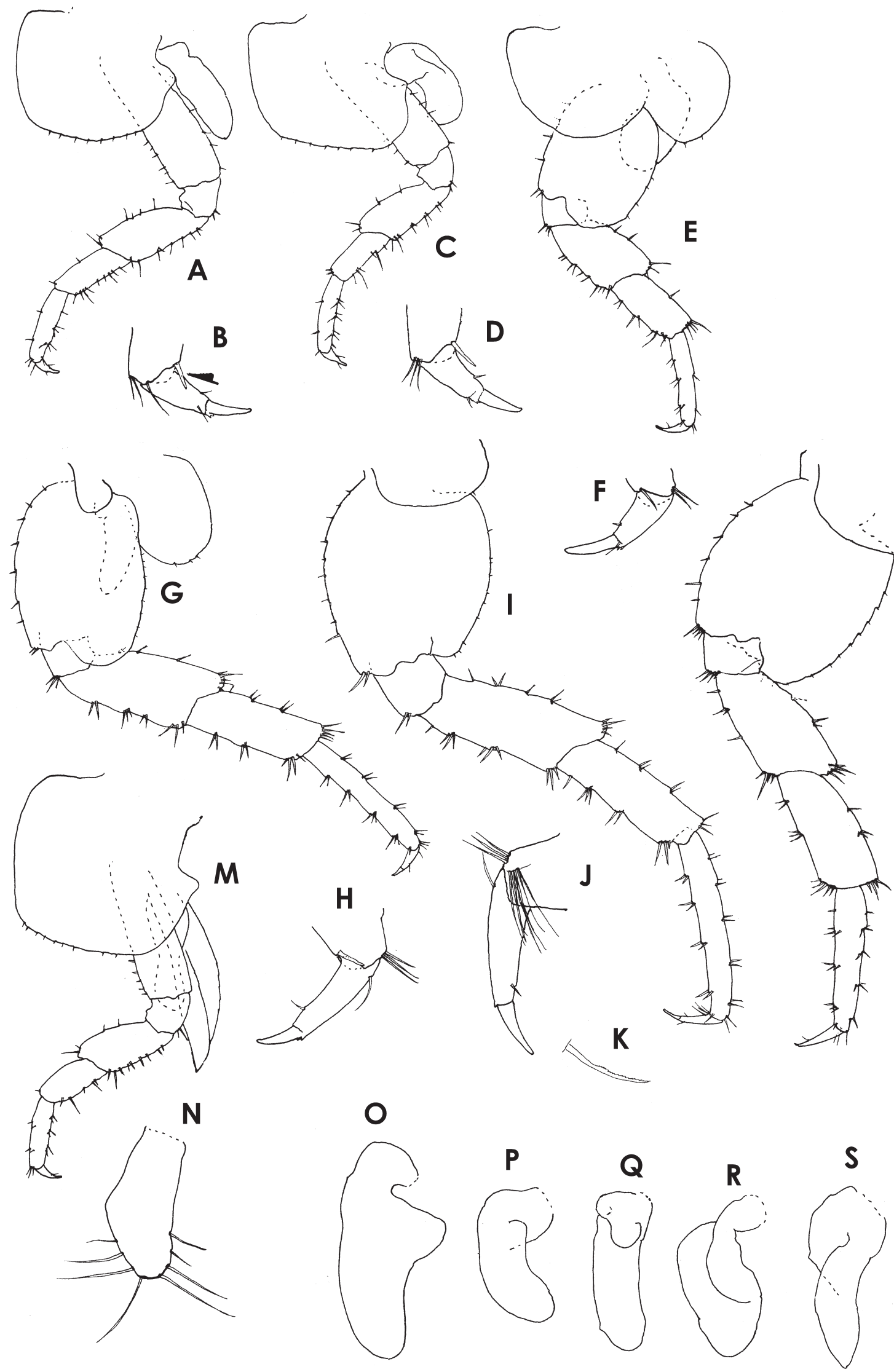

Fig. 4. Lowryella wadai gen. et sp. nov. Male $9.9 \mathrm{~mm}$ (holotype, NSMT-Cr 24358), A-K, O-S; ovig. female $8.2 \mathrm{~mm}$ (allotype, NSMT-Cr 24359 ), L-N. A, M, pereopod 3; C, E, G, pereopods 4-6; I, L, pereopod 7; B, D, F, H, J, distal parts of pereopods 3-7 (arrow in B points to locking robust-seta); K, enlarged serrate seta (distal half) on propodus of pereopod 7; N, oostegite of pereopod 5; O-S, coxal gills of gnathopod 2 and pereopods 3-6. Scale 1, $0.2 \mathrm{~mm}$ for B, D, F, H, and J; scale 2, $1 \mathrm{~mm}$ for A, C, E, G, and I; scale 3, $1 \mathrm{~mm}$ for L and M; scale $4,1 \mathrm{~mm}$ for $\mathrm{N}-\mathrm{S}, 0.1 \mathrm{~mm}$ for $\mathrm{K}$. 


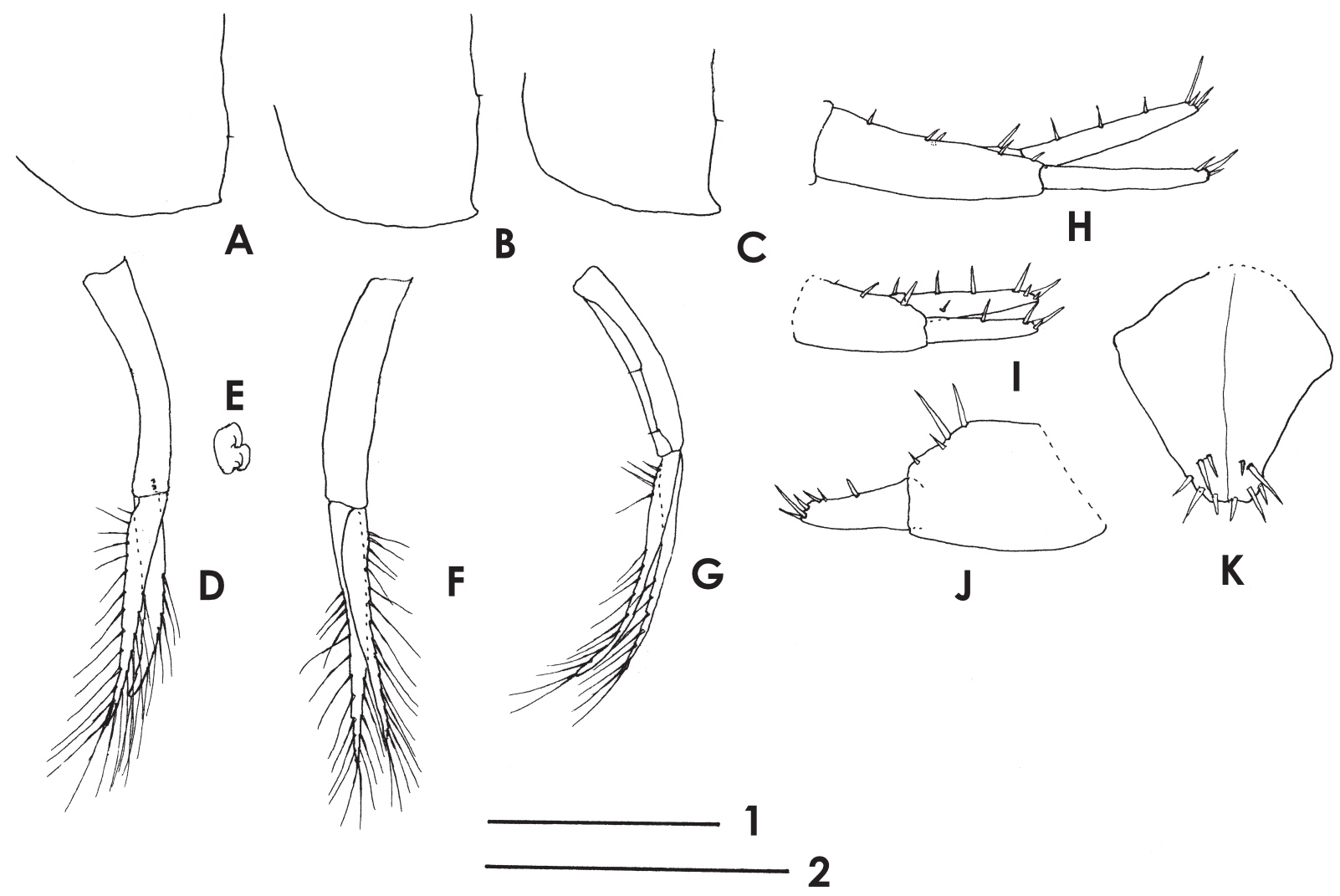

Fig. 5. Lowryella wadai gen. et sp. nov. Male $9.9 \mathrm{~mm}$ (holotype, NSMT-Cr 24358). A-C, pleonite side plates 1-3; D, F, G, pleopods 1-3; E, retinacula of pleopod 1; H-J, uropods 1-3; K, telson. Scale 1, $1 \mathrm{~mm}$ for A-D, F-I, $0.1 \mathrm{~mm}$ for E; scale 2, $0.5 \mathrm{~mm}$ for J and $\mathrm{K}$.

thopod 2 (Fig. 3P) with posterior cusp of coxa indistinct, palmar margin of propodus subequal to posterior margin in length, distal corner of palm weakly angulate, posterior margin parallel to anterior margin; dactylus robust. Locking robust-setae on propodi of pereopods 3-7 well-developed (Fig. 4B [arrow], D, F, H; not illustrated in Fig. 4J). Pereopods 3 (Fig. 4A) and 4 (Fig. 4C) each with coxa bearing weak posterior cusp. Pereopod 4 slightly shorter than pereopod 3. Pereopods 5 (Fig. 4E) and 6 (Fig. 4G) each with basis strongly lobate posteroventrally. Meri and carpi of pereopods 5-7 broad, $c a$. twice as wide as width of respective propodi. Pereopod 7 (Fig. 4I) with basis not lobate posteroventrally; propodus with $c a$. 10 serrate setae mediodistally (Fig. 4J, K).

Pleonite side plates (Fig. 5A-C) weakly acuminate posteroventrally, each posterior margin with single tiny seta. Peduncles of pleopods 1-3 (Fig. 5D, F, G) each with 2 retinacula (Fig. 5E), margins bare or with a few setae; rami with $8-10$ articles, as long as or slightly longer than respective peduncles.

Uropod 1 (Fig. 5H) with peduncle bearing 4 outer and 2 inner marginal robust setae; inner ramus with 3 dorsomarginal robust setae. Uropod 2 (Fig. 5I) with peduncle bearing 2 outer and 2 inner marginal robust setae; outer ramus with 1 marginal robust seta; inner ramus with 1 lateral and 2 dorsomarginal robust setae. Uropod 3 (Fig. 5J) with broad peduncle equipped with 4 robust setae on dorsal margin; ramus slightly shorter than peduncle, with 1 marginal and 5 apical robust setae. Telson (Fig. 5K) tapering distally, with suture in middle; each lobe with 2 subapical and 3 apical robust setae.

Description of female (Allotype, $8.2 \mathrm{~mm}$ ). Mandibles (Fig. 3H, I) as in generic diagnosis. Article 4 of maxillipedal palp reduced (Fig. 3J, K), masked by marginal setae on dorsal side and discernible from ventral side. Gnathopod 1 (Fig. $3 \mathrm{~N}, \mathrm{O}$ ) with basis and ischium each bearing small bulge with scabrous surface; merus and carpus lacking pellucid lobe; posterior margin of propodus slightly broadened distally, with scabrous surface; lateral surface of propodus with submarginal row of 5 setae; palmar margin transverse, slightly exceeding tip of dactylus. Gnathopod 2 (Fig. 3Q) with coxa bearing blunt posterior cusp, merus with distinct pellucid lobe. Pereopods more robust than those of male (see Fig. 4M and 4L for pereopods 3 and 7, respectively). Pereopod 7 with posteroventral lobe on basis; propodus lacking setal tuft at distal end. Oostegites of gnathopod 2 and pereopods 3 and 4 subovate with $c a$. 30 simple-tipped setae (Fig. 3R for oostegite of gnathopod 2). Oostegite of pereopod 5 small, with 7 setae (Fig. $4 \mathrm{~N}$ ).

Egg number 17 (paratype, NSMT-Cr 24361, $8.0 \mathrm{~mm}$ ).

Etymology. This species is named for Dr Keiji Wada, who has made great efforts in extensive surveys to elucidate the estuarine fauna in Japan, and who forwarded the present material to us for study.

Distribution. So far only known from estuarine Phragmites reed marshes at two localities (Shikoku and Kyushu) that face the Bungo Channel in western Japan (Fig. 1).

Remarks. In a smaller paratype female (NSMT-Cr 
$24361,8.0 \mathrm{~mm}$ ), the bulge on the posterodistal margin of the ischium is hardly developed but that on the basis is distinct. The allotype and paratypes display fewer articles in the antennal flagella than the holotype does: the number of articles of antennae 1 and 2 are three and eight ( $v$ s. four and 10 in the holotype), respectively. This is apparently correlated with body size $(8.0-8.2 \mathrm{~mm}$ in the allo- and paratypes $v s$. $9.9 \mathrm{~mm}$ in the holotype).

An extensive survey of tidal flats at 157 localities all over Japan, ranging from Hokkaido to Kyushu and including the Ryukyu and the Ogasawara Archipelagos, so far has revealed the presence of Platorchestia spp., Paciforchestia spp. (now Pyatakovestia Morino and Miyamoto, 2015; see Morino and Miyamoto 2015b), and Traskorchestia ochotensis (Brandt, 1851) in such habitats (Biodiversity Center of Japan 2007). Among that survey's samples, we discovered the present additional talitrid, Lowryella wadai gen. et sp. nov., at two adjacent localities in western Japan (Fig. 1). This may indicate a highly endemic distribution of this species, but the amphipod fauna of estuarine habitats in Japan, including reed marshes, has not so far received much attention. Further studies may expand the distributional range of this species or reveal related genera or species. Intensive sampling in selected estuarine reed marshes around western Japan may be one way of casting light on this subject.

\section{Acknowledgments}

We would like to express our hearty thanks to Professor Emeritus K. Wada of Nara Women's University for giving us the chance to study these valuable talitrid amphipods. Our deep gratitude is also due to Dr J. K. Lowry for his continuous encouragement and careful reading of the manuscript, and also to Dr J. Aoki for suggesting the name of the new talitrid. Dr M. J. Grygier of Lake Biwa Museum kindly provided many helpful suggestions to an earlier draft to improve the English, to whom we wish to acknowledge our debt. Dr H. Komatsu of the National Museum of Nature and Science and Dr K. Kakui of Hokkaido University helped us in many ways in preparing this article and we greatly appreciate their support.

\section{References}

Biodiversity Center of Japan. 2007. Dai 7 Kai Shizenkankyo Hozen Kisochosa. Senkai-iki Seitaikeichosa (Higatachosa) Hokokusho [The 7th Report of Basic Surveys for Natural Environment Protection: Ecological Survey of the Littoral Environment (Survey of Tidal Flats)]. Nature Conservation Bureau, Ministry of the Environment, Fujiyoshida, IV + 235 pp. + (99) pp. + CD. [In Japanese]

Bousfield, E. L. 1982. The amphipod superfamily Talitroidea in the northeastern Pacific region. I. Family Talitridae: systematics and distributional ecology. National Museums of Canada, Publications in Biological Oceanography 11: i-vii, 1-72.

Bousfield, E. L. 1984. Recent advances in the systematics and biogeography of land hoppers (Amphipoda: Talitridae) of the Indo-Pacific region. Bernice P. Bishop Museum Special Publication 72: 171210.

Bousfield, E. L. and Heard, R. W. 1986. Systematics, distributional ecology, and some host-parasite relationships of Uhlorchestia uhleri (Shoemaker) and U. spartinophila, new species (Crustacea: Amphipoda), endemic to salt marshes of the Atlantic coast of North America. Journal of Crustacean Biology 6: 264-274.

Friend, J. A. 1986. Biology of terrestrial amphipods. Annual Review of Entomology 31: 25-48.

Lowry, J. K. and Springthorpe, R. T. 2015a. The tropical talitrid genus Floresorchestia (Crustacea, Amphipoda, Talitridae). Zootaxa 3935: $1-68$.

Lowry, J. K. and Springthorpe, R. T. 2015b. Coastal Talitridae (Amphipoda: Talitridae) from north-western Australia to Darwin with a revision of the genus Cochinorchestia Lowry \& Peart, 2010. Zootaxa 3985: 151-202.

Morino, H. 2014. A new land-hopper genus, Mizuhorchestia, from Japan (Crustacea, Amphipoda, Talitridae). Bulletin of the National Museum of Nature and Science, Series A (Zoology) 40: 117-127.

Morino, H. and Miyamoto, H. 2015a. A new land-hopper genus, Nipponorchestia, with two new species from Japan (Crustacea, Amphipoda, Talitridae). Bulletin of the National Museum of Nature and Science, Series A (Zoology) 41: 1-13.

Morino, H. and Miyamoto, H. 2015b. Redefinition of Paciforchestia Bousfield, 1982 and description of Pyatakovestia gen. nov. (Crustacea, Amphipoda, Talitridae). Bulletin of the National Museum of Nature and Science, Series A (Zoology) 41: 105-121.

Rafinesque, C. S. 1815. Analyse de la nature ou tableu de l'unives a dês corps organisés. Palerme, $224 \mathrm{pp}$.

Richardson, A. M. M. and Mulcahy, M. E. 1996. The distribution of talitrid amphipods (Crustacea) on a salt marsh in southern Tasmania, in relation to vegetation and substratum. Estuarine, Coastal and Shelf Science 43: 801-817.

Wildish, D. J. 1988. Ecology and natural history of aquatic Talitroidea. Canadian Journal of Zoology 66: 2340-2359. 